\title{
The Association Between an Ultrabrief Cognitive Screening in Older Adults and Hospital Outcomes
}

\author{
Andrea M. Yevchak, PhD, RN¹, Kelly Doherty, BA², Elizabeth G. Archambault, MSW, LICSW², Brittany Kelly, BA, BSN, RN²,3,
} Jennifer R. Fonda, PhD, MA²,4, James L. Rudolph, MD, SM²,5,6*

${ }^{1}$ College of Nursing, The Pennsylvania State University, University Park, Pennsylvania; ${ }^{2}$ Geriatric Research, Education, and Clinical Center, VA Boston Healthcare System, Boston, Massachusetts; ${ }^{3}$ School of Nursing, Science and Health Professions, Regis College, Boston, Massachusetts; ${ }^{4}$ Department of Epidemiology, Boston University, Boston, Massachusetts; ${ }^{5}$ Division of Aging, Brigham and Women's Hospital, Boston, Massachusetts; ${ }^{6}$ Harvard Medical School, Boston, Massachusetts.

BACKGROUND: Though often recommended, hospital cognitive assessment is infrequently completed due to clinical and time constraints.

OBJECTIVE: This analysis aimed to evaluate the relationship between performance on ultrabrief cognitive screening instruments and hospital outcomes.

DESIGN: This is a secondary data analysis of a quality improvement project.

SETTING: Tertiary Veterans Administration hospital in New England.

PATIENTS: Patients, $\geq 60$ years old, admitted to the hospital.

\section{INTERVENTION: None.}

MEASUREMENTS: Upon admission, patients were administered 2 cognitive screening tools. The modified Richmond Agitation and Sedation Scale (mRASS) is a measure of arousal that can be completed in 15 seconds. The months of the year backward (MOYB) is a measure of attention that can be administered in $\leq 1$ minute. In-hospital outcomes included restraints and mortality, whereas discharge out- comes included length of stay, discharge not home, and variable direct costs. Risk ratios were calculated for dichotomous outcomes and unadjusted Poisson regression for continuous outcomes.

RESULTS: Patients $(n=3232)$ were screened. Altered arousal occurred in $15 \%$ of patients $(n=495)$; incorrect MOYB was recorded in $45 \%(n=1457)$. Relative to those with normal arousal and attention, those with abnormal mRASS and incorrect MOYB had increased length of stay (incident rate ratio [IRR]: 1.23, 95\% confidence interval $[\mathrm{Cl}]$ : 1.17-1.30); restraint use (risk ratio [RR]: 5.05, 95\% Cl: 3.29-7.75), in-hospital mortality (RR: 3.46, 95\% $\mathrm{Cl}$ : 1.24-9.63), and decreased discharge home (RR: 2.97, 95\% Cl: 2.42-3.64). Hospital variable direct costs were slightly, but not significantly, higher (IRR: 1.02, 95\% Cl: 0.88-1.17).

CONCLUSION: Impaired performance on ultrabrief cognitive assessments of arousal and attention provide valuable insights regarding hospital outcomes. Journal of Hospital Medicine 2015;10:651-657. (c) 2015 Society of Hospital Medicine.
Hospitalization is a critical time for older patients with cognitive impairment. Past research has found that hospitalized older adults with cognitive dysfunction have more rapid cognitive decline, increased morbidity and mortality, and higher costs of healthcare utilization. $^{1-3}$ Those with preexisting cognitive dysfunction, such as dementia, are most susceptible to the negative impacts of hospitalization. ${ }^{4-8}$ Identification of cognitive deficits upon admission is important

*Address for correspondence and reprint requests: James L. Rudolph, MD, VA Boston Healthcare System-GRECC, 150 S. Huntington Ave., Boston, MA 02130; Telephone: 857-364-6812; Fax: 857-364-4544; E-mail: jrudolph@partners.org

Published 2015. This article is a U.S. Government work and is in the public domain in the USA

Additional Supporting Information may be found in the online version of this article.

Received: June 5, 2015; Revised: July 31, 2015; Accepted: August 2 2015

2015 Society of Hospital Medicine DOI 10.1002/jhm.2450

Published online in Wiley Online Library (Wileyonlinelibrary.com). for risk stratification of patients and prevention of negative hospital health events.

Frontline healthcare providers are underequipped to detect acute cognitive dysfunction. ${ }^{9,10}$ Current practice and research for the detection of cognitive dysfunction in the acute care setting utilizes instruments that require training ${ }^{11}$ and are relatively lengthy $(>5$ minutes). ${ }^{12}$ Although these cognitive screening tests are accurate and reliable, the time requirement is not feasible in a fast-paced clinical setting. A possible alternative is the use of ultra-brief cognitive screening instruments $(<1$ minute $)$ that have the potential to identify those individuals requiring additional evaluation and follow-up. These brief instruments are composed of screening tools that emphasize core features of acute cognitive dysfunction such as level of arousal or attention. ${ }^{13-16}$ Arousal, the ability to respond to or interact with the environment, ${ }^{15}$ is an important component of cognition because it is generally preserved in chronic cognitive disorders (eg, dementia). Thus, an alteration in arousal may be a harbinger of more acute impairment ${ }^{17}$ in need of evaluation, and in these 
lowered states of arousal it may be difficult to test for attention. ${ }^{18}$ Attention is a broadly defined cognitive domain indicating focus. ${ }^{19}$ Older adults, regardless of preexisting cognitive dysfunction, warrant additional cognitive testing if levels of arousal or attention are altered $^{20,21}$ due to the significant relationship to delirium, which is associated with adverse events in this population. Recent research has demonstrated that these brief cognitive screening instruments provide information about the risk for delirium and are a strong test for clinical characteristics of delirium. ${ }^{16,21}$

The purpose of this analysis was to demonstrate the clinical outcomes of poor performance on ultrabrief assessments arousal and attention by frontline staff using a quality improvement database. Specific objectives include determining (1) the association of poor performance on brief cognitive assessments and hospital outcomes and (2) the inter-relationship between alterations in the levels of arousal and attention on inhospital and discharge outcomes.

\section{METHODS}

\section{Setting and Study Design}

This is a secondary analysis of data collected from a quality improvement program for delirium risk modification. ${ }^{22}$ This program collected data from October 2010 until September 2012 at a Veterans Affairs (VA) tertiary referral center for the New England region. Patients aged 60 years or older and admitted to medical wards were screened upon admission or transfer to VA Boston Healthcare System and provided appropriate interventions to modify delirium risk. Excluded were individuals admitted as observational status, or those readmitted within 30 days of initial screening, and those screened more than 72 hours after admission. Age and sex were abstracted from the medical record. Outcome data were collected from the medical record for the purpose of operating and sustaining the program. In a previous article, the length of stay (LOS) outcome was reported in a subset of this population. ${ }^{23}$ The analysis presented here includes the full cohort, presents the interaction with month of the year backward (MOYB), and provides additional outcomes not included in the other article. The VA institutional review board (IRB) reviewed and approved the secondary data analysis of the quality improvement project.

\section{Measures \\ Brief Cognitive Screening}

The baseline assessments of levels of arousal and attention were collected within 72 hours of admission to identify delirium risk. Trained study staff, not involved in the clinical care of patients, administered these assessments as part of the quality improvement project. It is estimated that these assessments took less than 1 minute to complete per individual, but actual administration time was not measured. Assessments were documented within the electronic health record as part of a delirium risk stratification system.

\section{Arousal}

The arousal level assessment was the modified Richmond Agitation and Sedation Scale (mRASS). The mRASS is a brief, reliable, observational tool used to determine arousal level. ${ }^{15,17}$ It is a text modification of the RASS ${ }^{17}$ for less acutely ill patients, capturing hyperactive and hypoactive altered levels of arousal. The mRASS asks an open-ended question followed by observation for 10 seconds and completion of a -5 to +4 rating scale. Alert and calm $($ score $=0)$ is considered normal, with positive numbers related to an increased level of arousal and attention, whereas negative numbers denote decreased levels. For the analyses, an mRASS of 0 is utilized as the reference. Categories were collapsed into $\geq 2$ and $\leq-2$ due to few patients on the extremes of the mRASS.

\section{Attention}

The MOYB is a brief measure of attention that is included in several instruments for delirium. ${ }^{19,24,25}$ For this study, the patient was asked to recite the 12 months backward beginning with December. A correct score was given if the individual was able to recite all 12 months to January without any error. An incorrect score was given if any mistake was made. Scoring for the MOYB is not standardized by age, preexisting medical diagnosis, or any other rational. ${ }^{26}$ Others have used July or June as a cutoff for a correct score on the MOYB, ${ }^{21,25}$ but a more conservative score of correct to January was used in this study, which has been previously used. ${ }^{26-30}$ A score of not completed was given when the patient was unable to participate or declined to complete the assessment. For the analysis, a correct score on the MOYB is the referent group.

\section{Outcomes}

In-hospital outcomes included (1) restraint use and (2) in-hospital mortality. Physical restraint use was identified by focused medical record review and identification of required restraint documentation, which, by center policy requires daily review and documentation. Any restraint use during the hospitalization was included.

Discharge outcomes included (1) LOS, (2) discharge other than a location to home, and (3) variable direct costs. LOS was calculated from date of admission until date of discharge. Discharge disposition was identified in the electronic medical record discharge documentation and categorized into discharge to the prehospital residence (home) or not. Hospital variable direct costs were collected from the VA decision support system, ${ }^{31}$ a centrally maintained administrative database. The VA decision support system is challenged with accounting for costs of a single-day 
admission and patients who are hospitalized from VA long-term care. To address the missing data from these cases, multiple imputations $(\mathrm{n}=20)$ of the missing data were performed. ${ }^{32}$ Sensitivity analyses were performed to determine the impact of the imputation and the cost analysis strategy (see Supporting Information, Appendix 1, in the online version of this article).

\section{Statistical Analyses}

For this analysis, outcomes are reported at each level of performance on the mRASS $(\leq-1$ to $\geq 1)$ and MOYB (correct, incorrect, not completed). For each analysis, the performance with a mean and standard deviation (SD) are reported for continuous outcomes and a percentage for dichotomous outcomes. For dichotomous outcomes, including restraint use, inhospital mortality, and discharge disposition, a risk ratio (RR) with $95 \%$ confidence interval $(\mathrm{CI})$ is presented. The median is presented for the cost data because variable direct cost is highly skewed. For LOS and cost outcomes, unadjusted incident rate ratio (IRR) from a Poisson regression relative to the referent is presented to compare the categories. A Poisson regression was selected because LOS (a count of days) and variable direct costs (a count of dollars) are highly skewed. The output of Poisson regression produces an IRR and $95 \%$ CI relative to the referent group. The Poisson regression could not be adjusted because the quality improvement nature of these data limited the number of covariates collected. Sensitivity analyses did not identify significant interactions of age and sex (results not shown).

MOYB was also compared by level of arousal (mRASS $=0$ vs all others). Due to the relatively few patients with positive mRASS, it was compressed into a category of abnormal mRASS relative to alert and calm. Similar to the previous analyses, Poisson regression was performed to calculate the IRR $(95 \% \mathrm{CI})$ relative to correct MOYB for the continuous variables. An RR was calculated for the dichotomous variables. All statistical analyses were performed using Stata version 11.0 (StataCorp, College Station, TX).

\section{RESULTS}

\section{Population Description}

Over the 2-year project timeline, a total of 3232 unique individual records were analyzed (Table 1). Patients admitted and screened within the prior 30 days $(\mathrm{n}=501)$ and patients screened more than 3 days after admission $(\mathrm{n}=664)$ were not included in the analysis. Older adults were on average 74.7 years old $(\mathrm{SD}=9.8)$, and $98.2 \%$ were male, consistent with the veteran population. Altered level of arousal, as defined by an abnormal mRASS score, was found in $15.3 \%$ of the population. Average LOS was 5.2 days $(\mathrm{SD}=5.6)$, restraint use occurred in $5.5 \%$ during the hospital stay, patients were likely to be discharged home $(71.7 \%)$, and a small portion died during hospitalization $(1.3 \%)$. Mean variable direct costs were $\$ 11,084$ with expected variability $(\mathrm{SD}=\$ 15,682$, median $\$ 6,614)$. Patients who died during the hospital

\section{TABLE 1. Baseline Characteristics}

\begin{tabular}{lc}
\hline Characteristic & Result, $\mathrm{N}=3,232$, Mean (SD) or \% (n) \\
\hline Age, $y$ & $74.7(9.8)$ \\
Male & $98.2(3,174)$ \\
mRASS & \\
$\leq-2$ & $2.0 \%(64)$ \\
-1 & $8.5 \%(273)$ \\
0 & $84.7 \%(2,737)$ \\
1 & $4.0 \%(131)$ \\
$\geq 2$ & $0.8 \%(27)$ \\
MOYB & \\
Correct & $48.8 \%(1,578)$ \\
Incorrect & $45.1 \%(1,457)$ \\
Not completed & $6.1 \%(197)$ \\
Restraint use & $5.5 \%(177)$ \\
In-hospital mortality & $1.3 \%(41)$ \\
Length of stay, d* & $5.1(5.4)$ \\
Discharge other than home & ${ }^{*}$ \\
Variable direct hospital cost, $\$^{*}$ & $71.7 \%(2,292)$ \\
Median cost, \$ & $11,084(15,682)$ \\
\hline
\end{tabular}

NOTE: Missing variable direct costs were imputed. Abbreviations: MOYB, months of the year backward; mRASS, Modified Richmond Agitation and Sedation Scale; SD, standard deviation.

*Length of stay, discharge to location other than home, and variable direct cost exclude patients who died during the hospitalization.

\begin{tabular}{|c|c|c|c|c|c|c|}
\hline & \multicolumn{2}{|c|}{ mRASS Alert and Calm, $n=2,737$} & \multicolumn{2}{|c|}{ mRASS Negative, $n=337$} & \multicolumn{2}{|c|}{ mRASS Positive, n = 158} \\
\hline & Value & IRR/RR (95\%Cl) & Value & IRR/RR (95\% Cl) & Value & IRR/RR (95\% Cl) \\
\hline Restraint use \% (n) & $4.2 \%(114)$ & Referent & $10.4 \%(35)$ & $2.49(1.74-3.57)$ & $17.7 \%(28)$ & $4.25(2.91-6.23)$ \\
\hline In-hospital mortality \% (n) & $1.0 \%(26)$ & Referent & $2.7 \%(9)$ & $2.81(1.33-5.55)$ & $1.3 \%(2)$ & $1.33(0.32-5.56)$ \\
\hline Length of stay, d (SD)* & $4.9(5.2)$ & Referent & $6.0(5.6)$ & $1.24(1.18-1.30)$ & $5.7(6.8)$ & $1.17(1.09-1.25)$ \\
\hline Discharge other than home, \% (n) ${ }^{*}$ & $24.9 \%(675)$ & Referent & $46.7 \%(153)$ & $1.87(1.64-2.14)$ & $48.1 \%(75)$ & $1.93(1.61-2.30)$ \\
\hline Variable direct cost, \$ $(S D)^{*, \dagger}$ & $10,581(14,928)$ & Referent & $11,604(13,852)$ & $1.10(0.95-1.26)$ & $10,640(10,771)$ & $1.01(0.85-1.19)$ \\
\hline Median cost, \$ & 6,318 & & 7,738 & & 7,858 & \\
\hline
\end{tabular}

NOTE: IRR is calculated for length of stay and cost. RR is calculated for restraint use, discharge home, and in-hospital mortality. Abbreviations: Cl, confidence interval; IRR, incident rate ratio; mRASS, Modified Richmond Agitation and Sedation Scale; RR, risk ratio; SD, standard deviation.

*Length of stay, discharge to location other than home, and variable direct cost exclude patients who died during the hospitalization.

${ }^{\dagger}$ Variable direct cost is calculated with imputation of missing cost data. 
stay had significantly longer LOS (mean 16.8 $[\mathrm{SD}=12.5]$ vs $5.1[\mathrm{SD}=5.4]$ days, $P<0.001)$ and higher variable direct costs $(\$ 43,879[\mathrm{SD}=\$ 37,334]$ vs $\$ 12,544 \quad[\mathrm{SD}=\$ 16,802], \quad P<0.001)$, justifying their removal from these analyses.

\section{Impact of Altered Level of Arousal on Outcomes}

There is an association between a deviation from a normal level of arousal (mRASS not equal to 0 ) and worsening outcomes (Table 2). Relative to a normal level of arousal (4.9 \pm SD 5.2 days), decreased level of arousal (negative mRASS), and increased arousal (positive mRASS) resulted in longer LOS $(6.0 \pm$ SD 5.6 days, $5.7 \pm$ SD 6.8 days, respectively). Similarly, increased or decreased arousal was associated with heightened risk of restraints and less frequent discharge to home. In-hospital mortality and hospital variable direct costs were significantly higher in those with decreased levels of arousal (IRR: 2.8, 95\% CI: 1.3-6.0; IRR: 1.10, 95\% CI: 0.95-1.26, respectively). The pattern does not hold for increased arousal with respect to in-hospital mortality and variable direct hospital cost outcomes. The unadjusted analysis found that, relative to normal arousal, there is a significant change in outcomes with decreased levels of arousal. Increased arousal is associated with worsened IRR in LOS, restraint use, and discharge home, but not inhospital mortality and variable direct cost.

\section{Impact of Altered Attention on Outcomes}

Patients who completed the MOYB incorrectly had increased restraint use (RR: 2.11, 95\% CI 1.44-3.11) and LOS (IRR: 1.06, 95\% CI: 1.02-1.10), but no difference in in-hospital mortality, discharge home (RR: 0.78, 95\% CI: $0.75-0.82$ ), and variable direct costs, relative to those who completed the MOYB correctly (Table 3). Importantly, patients who did not complete the MOYB assessment had a 2-fold increase in restraint use (RR: 2.05, 95\% CI: 0.94-4.50), inhospital mortality was nearly 6-fold higher (RR: 6.36, 95\% CI: 2.16-18.69), longer LOS (IRR: 1.12, 95\% CI: $1.03-1.21)$, and returned home less frequently (RR: $1.77,95 \%$ CI: 1.26-2.48).

\section{Inter-relationship of Altered Level of Arousal and Attention on Outcomes}

The inter-relationship of altered level of arousal and attention is presented in Table 3. Of patients with a normal mRASS, $52 \%$ had correct MOYB. The percentage of correct MOYB declined with the level of arousal, such that $38 \%$ had normal MOYB and a mRASS of -1 and $9 \%$ had normal MOYB with mRASS of $\leq-2$. In general, in-hospital outcomes (restraints and mortality) are associated with MOYB performance, and discharge outcomes (LOS, discharge location, and variable direct costs) are associated with mRASS. Those patients who did not complete the MOYB demonstrated worse outcomes, regardless of

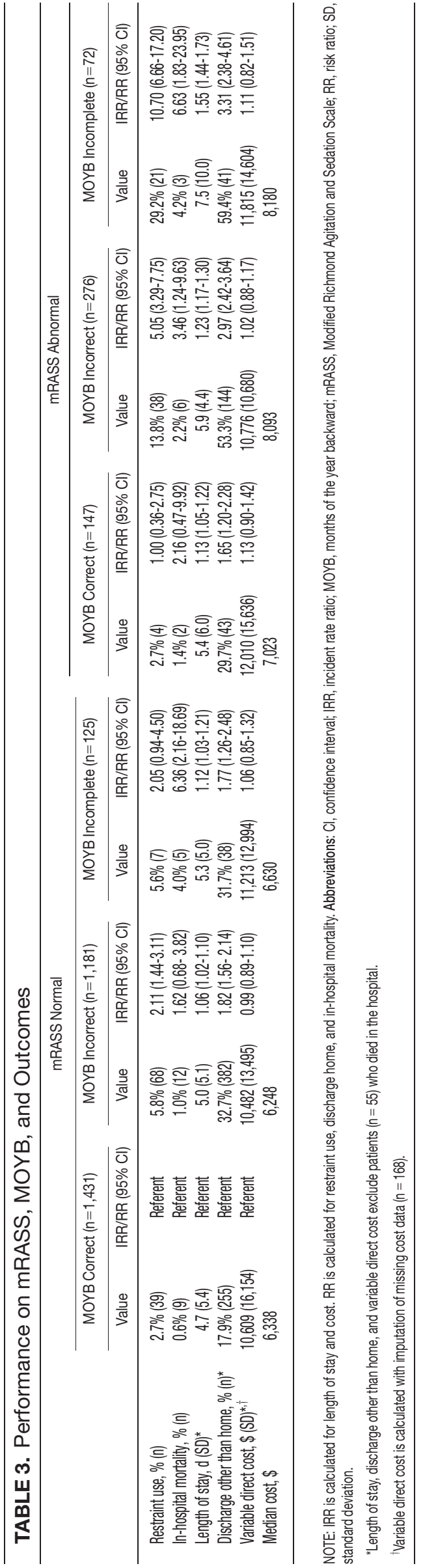




\begin{tabular}{|c|c|c|c|c|c|c|c|c|c|c|}
\hline \multicolumn{11}{|c|}{ Step 1: Modified Richmond Agitation and Sedation Scale (mRASS): } \\
\hline \multicolumn{11}{|c|}{ Scoring of mRASS: } \\
\hline+4 & +3 & +2 & & & 0 & -1 & -2 & -3 & -4 & -5 \\
\hline $\begin{array}{c}\text { Highly } \\
\text { Combative }\end{array}$ & $\begin{array}{c}\text { Very } \\
\text { Agitated }\end{array}$ & $\begin{array}{l}\text { Slightly } \\
\text { Agitated }\end{array}$ & $\begin{array}{r}N \\
\text { Restl }\end{array}$ & id & $\begin{array}{c}\text { Alert } \\
\text { and Calm }\end{array}$ & $\begin{array}{l}\text { Wakes } \\
\text { Easily }\end{array}$ & $\begin{array}{l}\text { Wakes } \\
\text { Slowly }\end{array}$ & $\begin{array}{l}\text { Difficulty } \\
\text { Waking }\end{array}$ & $\begin{array}{l}\text { Falls } \\
\text { Asleep }\end{array}$ & $\begin{array}{c}\text { Not } \\
\text { Arousable }\end{array}$ \\
\hline $\begin{array}{l}\text { Aggressive, } \\
\text { Dangerous }\end{array}$ & $\begin{array}{l}\text { Cannot } \\
\text { Focus }\end{array}$ & $\begin{array}{c}\text { Easily } \\
\text { Distractible }\end{array}$ & $\begin{aligned} \text { Anx } \\
\text { Coop }\end{aligned}$ & $\begin{array}{l}\text { ous, } \\
\text { rative }\end{array}$ & $\begin{array}{l}\text { Appropriate } \\
\text { Response }\end{array}$ & $\begin{array}{l}\text { Slightly } \\
\text { Drowsy }\end{array}$ & $\begin{array}{l}\text { Briefly } \\
\text { Awake }\end{array}$ & $\begin{array}{l}\text { No Eye } \\
\text { Contact }\end{array}$ & $\begin{array}{l}\text { Physical } \\
\text { Prompt }\end{array}$ & $\begin{array}{c}\text { No } \\
\text { Response }\end{array}$ \\
\hline \multicolumn{11}{|c|}{ Step 2: Months of the Year Backwards (MOYB): } \\
\hline \multicolumn{11}{|c|}{$\begin{array}{l}\text { Ask the patient to 'State the months of the year backwards starting with December'. } \\
\text { If appropriate answer for all } 12 \text { months, correct score. } \\
\text { Use prompts such as, 'Can you tell me what is the month that comes before December?' if patient does not answer. } \\
\text { If the patient responds, but stops, continue with prompts as above until } 2 \text { prompts have been given. }\end{array}$} \\
\hline \multicolumn{11}{|c|}{ Scoring of MOYB: } \\
\hline \multicolumn{5}{|c|}{ Correct } & \multicolumn{6}{|c|}{ Incorrect } \\
\hline \multicolumn{5}{|c|}{ States MOYB with less than 2 prompts. } & \multicolumn{6}{|c|}{ Needs more than 2 prompts or error without self-correcting. } \\
\hline \multicolumn{11}{|c|}{ Next Steps all Include Continued Monitoring of Patient: } \\
\hline \multicolumn{4}{|c|}{$\begin{array}{c}\text { mRASS is 0; } \\
\text { MOYB Correct }\end{array}$} & \multicolumn{4}{|c|}{$\begin{array}{l}\text { mRASS NOT 0; } \underline{O R} \\
\text { MOYB Incorrect }\end{array}$} & \multicolumn{3}{|c|}{$\begin{array}{c}\text { mRASS NOT 0; AND } \\
\text { MOYB Incorrect }\end{array}$} \\
\hline \multicolumn{4}{|c|}{$\begin{array}{l}\text { Consider assessments every shift or at least once each } \\
\text { day. }\end{array}$} & \multicolumn{4}{|c|}{$\begin{array}{l}\text { Additional assessments to determine type of cognitive } \\
\text { impairment. }\end{array}$} & \multicolumn{3}{|c|}{$\begin{array}{l}\text { Complete further cognitive assessments for } \\
\text { delirium. }\end{array}$} \\
\hline
\end{tabular}

FIG. 1. How to use the mRASS and MOYB in clinical settings. Abbreviations: MOYB, months of the year backward; mRASS, Modified Richmond Agitation and Sedation Scale.

mRASS performance, including a 6 -fold increase in mortality and significant increases in LOS and discharge location.

\section{DISCUSSION}

Impaired performance on a one-time assessment of arousal or attention during hospitalization demonstrated a relationship with in-hospital and discharge outcomes. Relative to normal levels of arousal and attention, alterations in attention, level of arousal, or both were associated with progressively negative consequences. Combined with the prognostic value, the administration of ultra-brief cognitive screening measures may have value in the identification of patients who would benefit from additional screening, supporting prior work in this area. ${ }^{23}$ The brevity of the assessments enhances clinical utility and implementation potential.

Cognitive function during hospitalization has been associated with many negative outcomes including delirium, falls, pressure ulcers, and functional decline., ${ }^{3,33}$ The findings of this analysis are consistent with previous studies and provide important clinical implications. First, prior work in cognitive screening has focused on more time-consuming instruments. ${ }^{12}$ By focusing on brief instruments, particularly those under 1 minute that do not require paper or props, a user-friendly tool that is associated with health outcomes is provided.
In addition, this analysis demonstrates that each assessment, when used individually, has some prognostic significance associated with the identification of delirium or other types of cognitive impairment. When used alone, abnormal scores on the mRASS or MOYB may be indicative of individuals requiring further cognitive assessment, supporting previous research. ${ }^{16,23}$ Individuals with abnormal scores on both the mRASS and MOYB identify a high-risk group in need of further clinical assessment for delirium (Figure 1). Neither of these assessments are meant to be used as the only means to diagnosis delirium, but together they identify key clinical characteristics of delirium (arousal and attention). ${ }^{16,18,21}$ Considering the significant negative consequences associated with delirium, it is not surprising that tools identifying core features of delirium, such as those presented here, would also be associated with in-hospital and discharge outcomes.

The quality improvement design of this project allowed the recording of outcomes in those who were unable or refused to complete the screening. This may be a potentially high-risk group who would otherwise go unnoticed. A recent editorial from the American and European Delirium Societies highlights that individuals who are unable or refuse to complete testing due to impaired arousal are neglected in the most recent American Psychiatric Association Diagnostic and Statistical Manual of Mental Disorders, Fifth Edition definition of delirium. ${ }^{18}$ Further work to identify 
and intervene on behalf of individuals who are unable to complete testing will aid in understanding arousal and its relationship to delirium and other disorders.

This analysis provides additional insight in the selection of measures of arousal and attention. Level of arousal is a complex concept that involves components of awareness and alertness, including external stimuli and self-awareness. ${ }^{38-40}$ As an ultra-brief measure of arousal level, the mRASS incorporates both external stimuli (asking an open-ended question) and self-awareness (describing current state) to determine basic cognitive function. Attention can be defined as the selection of stimuli for further cognitive processing. ${ }^{40}$ Attention is an umbrella term referring to many cognitive processes, ranging from sustained attention and working memory to executive function such as set shifting and multitasking. Ultra-brief measures of attention, such as MOYB, are basic tasks of sustained attention with components of working memory. ${ }^{19} \mathrm{An}$ alteration in attention may be indicative of a more significant global change in cognition ${ }^{41}$ beyond basic cognitive function assessed by administration of the mRASS, such as delirium. ${ }^{42}$ The relationship between level of arousal and attention is complex, and arguments have been made that one has to have a certain level of arousal to attend to a stimuli, whereas others have found that one has to have a certain level of attention. ${ }^{18,39,40}$ Administration of both the mRASS and MOYB is a useful bedside tool for clinicians to examine both basic cognitive function and more complex tasks of attention.

The quality improvement nature of this work has limitations and strengths that deserve mention. The significant strength of this work is the robust sample size. Also, trained staff not involved in the direct clinical care of patients administered the cognitive screens, suggesting that non-clinically trained personnel could be utilized for risk assessment. The major limitation is the restricted amount of covariate data that were collected. Data for this project were collected to operationalize and demonstrate the impact and business case of a delirium risk modification program, ${ }^{17}$ limiting the ability to perform adjustment for other covariates such as comorbidity and reason for admission. Also, due to the nature of this project, a diagnosis of delirium was not determined. A limitation of excluding in-hospital deaths from the cost analysis was that some individuals at high risk died early, thus costing less overall. Generalizability is limited by an overrepresentation of males within a single setting. Further use and understanding of mRASS and MOYB in other population is warranted and welcomed. Use of MOYB is also a limitation considering that scores are not standardized across patients or settings. ${ }^{26}$ Data regarding administration time of either of these tools were not collected; therefore, determining that these are ultra-brief assessments ( $<1$ minute) is based on estimates. As such, these measures should not be the sole source of information for clinical evaluation and diagnosis.

\section{CONCLUSION}

This work found that impaired performance on brief cognitive assessments of arousal and attention in hospitalized patients were associated with restraint use, in-hospital mortality, longer LOS, less discharge home, and hospital costs. Routine screening of older patients with brief, user-friendly cognitive assessments upon admission can identify those who would benefit from additional assessment and intervention to alleviate individual and economic burdens.

\section{Acknowledgements}

The authors are indebted to the veterans who participated in their delirium and fall reduction programs. The authors are thankful for the guidance of the VA Boston Healthcare System Delirium Task Force and Patient Safety Officers for continued collaboration to improve outcomes for the veterans they serve.

Disclosures: Dr. Yevchak and Ms. Doherty contributed equally to this article and agreed to share first authorship. This material is based upon work supported by the Department of Veterans Affairs Office of Patient Safety Delirium Patient Safety Center of Inquiry and a Geriatrics and Extended Care T21 Alternative to Non-institutional Long Term Care award. Archambault, Doherty, Fonda, Kelly, and Rudolph are employees of the US government. Dr. Rudolph also received support from a VA Career Development Award. The views expressed in this article are those of the authors and do not necessarily reflect the position or policy of the Department of Veterans Affairs or the United States Government. The authors report no conflicts of interest.

\section{References}

1. Bellelli G, Frisoni G, Turco R, Lucchi E, Magnifico F, Trabucchi M. Delirium superimposed on dementia predicts 12-month survival in elderly patients discharged from a postacute rehabilitation facility. J Gerontol A Biol Sci Med Sci. 2007;62(11):1306-1309.

2. Fick DM, Steis MR, Waller JL, Inouye SK. Delirium superimposed on dementia is associated with prolonged length of stay and poor outcomes in hospitalized older adults. J Hosp Med. 2013;8(9):500-505.

3. Boustani M, Baker M, Campbell N, et al. Impact and recognition of cognitive impairment among hospitalized elders. J Hosp Med. 2010; 5(2):69-75.

4. Hughes CG, Morandi A, Girard TD, et al. Association between endothelial dysfunction and acute brain dysfunction during critical illness. Anesthesiology. 2013;118(3):631-639.

5. Fong TG, Jones RN, Shi P, et al. Delirium accelerates cognitive decline in Alzheimer disease. Neurology. 2009;72(18):1570-1575.

6. Fong TG, Jones RN, Marcantonio ER, et al. Adverse outcomes after hospitalization and delirium in persons with Alzheimer disease. Ann Intern Med. 2012;156(12):848-856.

7. Rudolph JL, Inouye SK, Jones RN, et al. Delirium: an independent predictor of functional decline after cardiac surgery. J Am Geriatr Soc. 2010;58(4):643-649.

8. Leslie D, Inouye SK. The importance of delirium: economic and societal costs. J Am Geriatr Soc. 2011;59:S241-S243.

9. Yevchak AM, Steis MR, Diehl T, Hill NL, Kolanowski AM, Fick DM. Managing delirium in the acute care setting: a pilot focus group study. Int J Older People Nurs. 2012;7(2):152-162.

10. Yevchak A, Fick DM, McDowell J, et al. Barriers and facilitators to implementing delirium rounds in a clinical trial across three diverse hospital settings. Clin Nurs Res. 2014;23(2):201-215.

11. Ryan K, Leonard M, Guerin S, Donnelly S, Conroy M, Meagher D. Validation of the confusion assessment method in the palliative care setting. Palliat Med. 2009;23(1):40-45.

12. Wong CL, Holroyd-Leduc J, Simel DL, Straus SE. Does this patient have delirium? Value of bedside instruments. JAMA. 2010;304(7): 779-786.

13. Franco JG, Trzepacz PT, Meagher DJ, et al. Three core domains of delirium validated using exploratory and confirmatory factor analyses. Psychosomatics. 2013;54(3):227-238.

14. Krishnan V, Leung LY, Caplan LR. A neurologist's approach to delirium: diagnosis and management of toxic metabolic encephalopathies. Eur J Intern Med. 2014;25(2):112-116.

15. Chester JG, Beth Harrington M, Rudolph JL; the VADWG. Serial administration of a modified Richmond Agitation and Sedation Scale for delirium screening. J Hosp Med. 2012;7(5):450-453. 
16. Han JHJH. The diagnostic performance of the Richmond Agitation Sedation Scale for detecting delirium in older emergency department patients. Acad Emerg Med. 2015;22(7):878-882.

17. Sessler CN, Gosnell MS, Grap MJ, et al. The Richmond Agitation Sedation Scale: validity and reliability in adult intensive care unit patients. Am J Respir Crit Care Med. 2002;166(10):1338-1344.

18. European Delirium Association, American Delirium Society. The DSM-5 criteria, level of arousal and delirium diagnosis: inclusiveness is safer. BMC Med. 2014;12:141.

19. Kolanowski AM, Fick DM, Yevchak AM, Hill NL, Mulhall P, McDowell J. Pay attention! The critical importance of assessing attention in older adults with dementia. J Gerontol Nurs. 2012; 38(11):23-27.

20. Eeles E, Pandy S, Ray JL. Delirium: a disorder of consciousness? Med Hypotheses. 2013;80(4):399-404.

21. O'Regan NA, Ryan DJ, Boland E, et al. Attention! A good bedside test for delirium? J Neurol Neurosurg Psychiatry. 2014;85(10):11221131.

22. Rudolph JL, Archambault E, Kelly B. A delirium risk modification program is associated with hospital outcomes. J Am Med Dir Assoc. 2014;15(12):11.

23. Yevchak AM, Han JH, Doherty K, et al. Impaired arousal in older adults is associated with prolonged hospital stay and discharge to skilled nursing facility. I Am Med Dir Assoc. 2015;16(7):586-589.

24. Bellelli G, Morandi A, Davis DHJ, et al. Validation of the 4AT, a new instrument for rapid delirium screening: a study in 234 hospitalised older people. Age Ageing. 2014;43(4):496-502.

25. Simon SE, Bergmann MA, Jones RN, Murphy KM, Orav EJ, Marcantonio ER. Reliability of a structured assessment for nonclinicians to detect delirium among new admissions to postacute care. I Am Med Dir Assoc. 2006;7(7):412-415.

26. Cunningham E, Passmore A, McAuley D, McGuinness B. Reciting the months of the year backwards: what is a 'normal' score? Age Ageing. 2015;44(3):537-538.

27. Rudolph JL, Archambault E, Kelly B. A Delirium risk modification program is associated with hospital outcomes. J Am Med Dir Assoc. 2014;15(12):957.e957-957.e911.

28. Marcantonio ER, Ngo LH, O'Connor M, et al. 3D-CAM: derivation and validation of a 3-minute diagnostic interview for CAM-defined delirium: a cross-sectional diagnostic test study. Ann Intern Med. 2014;161(8):554-561.

29. Simon S, Bergmann M, Jones R, Murphy K, Orav E, Marcantonio E. Reliability of a structured assessment for non-clinicians to detect delir- ium among new admissions to post-acute care. J Am Med Dir Assoc. 2006;7:412-415.

30. Rudolph JL, Jones RN, Levkoff SE, et al. Derivation and validation of a preoperative prediction rule for delirium after cardiac surgery. Circulation. 2009;119(2):229-236.

31. Barnett PG, Rodgers JH. Use of the Decision Support System for VA cost-effectiveness research. Med Care. 1999;37(4 suppl Va):AS63AS70.

32. Swindle R, Lukas CV, Meyer DA, Barnett PG, Hendricks AM. Cost analysis in the Department of Veterans Affairs: consensus and future directions. Med Care. 1999;37(4 Suppl Va):AS3-AS8.

33. Inouye SK, Schlesinger MJ, Lydon TJ. Delirium: a symptom of how hospital care is failing older persons and a window to improve quality of hospital care. Am J Med. 1999;106(5):565-573.

34. Inouye SK, Bogardus ST, Charpentier PA, et al. A multicomponent intervention to prevent delirium in hospitalized older patients. $N \mathrm{Engl}$ J Med. 1999;340(9):669-676.

35. Frels C, Williams P, Narayanan S, Gariballa SE. Iatrogenic causes of falls in hospitalised elderly patients: a case-control study. Postgrad Med J. 2002;78(922):487-489.

36. Enns E, Rhemtulla R, Ewa V, Fruetel K, Holroyd-Leduc JM. A controlled quality improvement trial to reduce the use of physical restraints in older hospitalized adults. J Am Geriatr Soc. 2014;62(3): 541-545.

37. Hung WW, Ross JS, Farber J, Siu AL. Evaluation of the mobile acute care of the elderly (mace) service. JAMA Intern Med. 2013;173(11): 990-996.

38. Vithoulkas G, Muresanu DF. Conscience and consciousness: a definition. J Med Life. 2014;7(1):104-108.

39. Boly M, Seth A, Wilke M, et al. Consciousness in humans and nonhuman animals: recent advances and future directions. Front Psychol. 2013;4:625.

40. Srinivasan N. Interdependence of attention and consciousness. In: Rahul B, Bikas KC, eds. Progress in Brain Research. Vol. 168. New York, NY: Elsevier; 2007:65-75.

41. Rajlakshmi AK, Mattoo SK, Grover S. Relationship between cognitive and non-cognitive symptoms of delirium. Asian J Psychiatr. 2013; 6(2):106-112

42. Inouye SK, van Dyck CH, Alessi CA, Balkin S, Siegal AP, Horwitz RI. Clarifying confusion: the confusion assessment method. A new method for detection of delirium. Ann Intern Med. 1990;113(12): 941-948. 